\title{
Antibiotic determination of antibiotic susceptibility testing disks using liquid chromatography and microbiological assay
}

\section{Abstract}

Introduction: The aim of this work was to control the quality of some antibiotics cartridges (ampicillin, amoxicillin-clavulanic acid, ciprofloxacin and vancomycin) used for antibiotic susceptibility testing by disk diffusion method. Antibiotics were determined using disks and two techniques were compared for this purpose, chromatographic and microbiological method at constant temperature.

Methods: Chromatographic method (High-Performance Liquid Chromatography: HPLC) was used for determining ampicillin, amoxicillinclavulanic acid and ciprofloxacin, and microbiological method for vancomycin and ampicillin.

Results: Dosage results reveal that $35 \%$ of unexpired cartridges had low content and all the expired AB's disks revealed low results.

Conclusion: This study demonstrated that the content of antibiotics in disks could be decreased if the storage and transport conditions (temperature and relative humidity) of disk cartridges were not respected. Therefore, properly performed quality control of antibiotic disks before use in laboratories would aid in providing accurate and reproducible results of dosage.

\section{Keywords}

Antibiotic Disks; Quality Control; Antibiogram; High Performance Liquid

Chromatography; Microbiological Method.
Amine Ousaid ${ }^{1}$, Jaouad Akrim1, Youssef Khayati $^{1}$

1 Laboratory of Drug Sciences, Biomedical and Biotechnological Research, Faculty of Medicine and Pharmacy, Hassan II University. Casablanca. Morocco.

\section{Contact information:}

Dr. Amine Ousaid.

झ dr.amine.ousaid@gmail.com

\section{Introduction}

Antibiotics are a group of drugs used to treat various infections caused by bacteria and some antibiotics are effective only against specific 
bacteria types. Therefore, antibiotic susceptibility testing (AST) is usually carried out to determine which antibiotic will be most successful in treating a bacterial infection in vivo and the results of the test are reported on antibiogram form with defined categories (susceptible, intermediate and resistant) [1]. Clinicians consider these interpretations to determine which antibiotic might be effective in treating their patients.

There are few tests used in determination of antibiogram of bacteria but the disk diffusion is the most practical method and is still the method of choice for the average laboratory.

In this method, disks impregnated with antimicrobial agents are used. The disks are placed onto agar plates, which are pre-inoculated with the suspension of the microorganism being tested. The basic principle of the method is the diffusion of the antimicrobial agent into the medium, which occurs when the disks come into contact with the moist surface of the plate. The concentration of the agent reduces logarithmically as the distance from the disk is increased. After the incubation period, the plates are observed for the circular inhibition zone created around the disk, which is due to the inhibitory effect of the antimicrobial agent on the microorganism [1].

The procedure is very sensitive to changes in test conditions. Therefore, it is crucial that each variable in the procedure should be standardized and carefully controlled.

Owing to the numerous variables that may affect the results, rigorous quality control is of utmost importance for susceptibility testing.

The objective of this study was to verify the contents of antimicrobial disks used in disk diffusion method. Four antibiotics were used ampicillin, amoxicillin-clavulanic acid, ciprofloxacin and vancomycin, and analyzed by a chromatographic technique (HPLC) and microbiological method[2, 3].

\section{Methods}

\section{Instrumentation}

The HPLC system (Perkin Elmer Flexar) with UVIVis detector was used. The device was monitored and processed using Total Chrom software. The cold accumulators were used for transporting the cartridges, a refrigerator (Liebherr Premium) for the conservation, analytical balances (Mettler Toledo AG 285 and Shimadzu BW 4200H) and an autoclave RAYPA AE150.

For the microbiological method, we used an incubator BD BINDER 240, Water bath (Memmert) and microbiological safety cabinet with Bunsen burners.

\section{Chemicals and reagents}

All the Reagents and solvents used in our work are HPLC-R.

Antibiotic standards were of high purity grade (> 90\%) and were purchased from United States Pharmacopeia (USP) Reference Standards. Distilled water was obtained by the GFL water distiller.

Phosphoric acid $\mathrm{H}_{3} \mathrm{PO}_{4}$, chlorhydric acid $\mathrm{HCl}$, acetic acid, sodium dihydrogen phosphate dihydrate $\left(\mathrm{NaH}_{2} \mathrm{PO}_{4}, 2 \mathrm{H}_{2} \mathrm{O}\right)$, monopotassium phosphate $\mathrm{KH}_{2} \mathrm{PO}_{4}$, methanol $\mathrm{CH}_{3} \mathrm{OH}$, triethylamine and acetonitrile were provided by Solvachim (Casablanca, Morocco).

\section{Samples}

We used ATB disk's cartridges from four health centers provided by the laboratories of medical microbiology as shown in (Table 1).

All cartridges were stored at temperature of + $4^{\circ} \mathrm{C}$ in the refrigerator.

The methods for determination of ampicillin and ciprofloxacin and the microbiological technique were followed the procedures described in the European Pharmacopoeia monographs EP 8th edition (8.0). While, the method for determining amoxicillin is described in the method published in 2015 by Ramli $Y$ et Al. [4] 
Table 1. Sources of disk cartridges

\begin{tabular}{|c|c|c|c|c|c|c|}
\hline \multirow{2}{*}{$\begin{array}{c}\text { Sources } \\
\text { Manufacturers }\end{array}$} & \multicolumn{2}{|c|}{$\begin{array}{c}\text { Ibn Rochd University } \\
\text { Hospital }\end{array}$} & \multirow{2}{*}{$\begin{array}{c}\text { Morocco National } \\
\text { Institute of Hygiene } \\
\text { Oxoid France }\end{array}$} & \multirow{2}{*}{$\begin{array}{l}\text { Pasteur Institute } \\
\text { of Morocco } \\
\text { Oxoid France }\end{array}$} & \multicolumn{2}{|c|}{ Ibn Sina University Hospital } \\
\hline & $\begin{array}{l}\text { Oxoid } \\
\text { France }\end{array}$ & $\begin{array}{l}\text { Bioanalyse } \\
\text { Turkey }\end{array}$ & & & $\begin{array}{l}\text { Oxoid } \\
\text { France }\end{array}$ & $\begin{array}{l}\text { Mast Diagnostics } \\
\text { France }\end{array}$ \\
\hline $\begin{array}{l}\text { Amoxicillin/clavulanic } \\
\text { acide }(20 / 10 \mu \mathrm{g}) *\end{array}$ & $E_{1}$ & $E_{2}$ & $\mathrm{E}_{5}$ ** & $E_{8}$ & $\mathrm{E}_{12}$ & $\mathrm{E}_{13}$ \\
\hline Ampicillin $(10 \mu g)$ & - & - & $\mathrm{E}_{6}^{* *}$ & $E_{9}$ & $E_{14}$ & $E_{15}$ \\
\hline Ciprofloxacin $(5 \mu \mathrm{g})$ & $E_{3}$ & - & - & $E_{10}$ & $E_{16}$ & - \\
\hline Vancomycin $(30 \mu \mathrm{g})$ & $E_{4}$ & - & $\mathrm{E}_{7}$ ** & $E_{11}$ & $E_{17}$ & - \\
\hline
\end{tabular}

A simple, fast, economical, accurate, precise and reproducible RP - HPLC method with ultraviolet detection at $220 \mathrm{~nm}$, a valid method for the simultaneous determination of Amoxicilline and Clavulanique acid with a good chromatographic separation between both compounds using a reversed phase $\mathrm{C} 18$ column and a mobile phase, consisting of Acetonitril/NaH2PO4. buffer $\mathrm{pH}=$ 4.4). The method was validated in terms of specificity, linearity, precision, accuracy, and robustness. This fully validated method, which allows the simultaneous measurement of amoxicillin and clavulanic acid in different formulations, is rapid (total run time $<7 \mathrm{~min}$ ).

\section{Chromatographic conditions}

The mobile phase of chromatographic method was as follow:

\section{For amoxicillin}

(90 V; 10V) buffer and acetonitrile R. The buffer was prepared by dissolving $5.15 \mathrm{~g}$ of sodium dihydrogen phosphate dihydrate $\left(\mathrm{NaH}_{2} \mathrm{PO}_{4}, 2 \mathrm{H}_{2} \mathrm{O}\right)$ in 11 of $\mathrm{H}_{2} \mathrm{O}$ $\mathrm{R}$ and adjusted at $\mathrm{pH} 6.35$ (instead of 4.4) for a better separation of the peaks. The solution was mixed, degassed and filtered [4].

\section{For ampicillin}

$(0.5 \mathrm{ml} ; 50 \mathrm{ml} ; 50 \mathrm{ml}$; qf $1000 \mathrm{ml})$ diluted acetic acid $\mathrm{R}$, monopotassic phosphate solution $0.2 \mathrm{M} \mathrm{R}$, acetonitrile $\mathrm{R}$ and $\mathrm{H}_{2} \mathrm{O}$ R. Diluted acetic acid was prepared by dissolving $12 \mathrm{~g}$ of acetic acid in $100 \mathrm{ml}$ of $\mathrm{H}_{2} \mathrm{O}$ and monopotassic phosphate solution by dissolving $2.72 \mathrm{~g}$ of monopotassium phosphate in $100 \mathrm{ml}$ of $\mathrm{H}_{2} \mathrm{O}$.

\section{For ciprofloxacin}

(13 V; 87 V) Acetonitrile R; phosphoric acid R. Phosphoric acid $\mathrm{R}$ was prepared by dissolving $2.45 \mathrm{~g}$ of phosphoric acid in 1 (one liter) of distilled water and the $\mathrm{pH}$ was adjusted to 3.0 using triethylamine $\mathrm{R}$ solution.

The microbiological technique includes a buffer was prepared with $50 \mathrm{ml}$ of monopotassic phosphate solution $0.2 \mathrm{M} \mathrm{R}$ and $29.63 \mathrm{ml}$ sodium hydroxide $0.2 \mathrm{M} \mathrm{R}$ for $\mathrm{a} \mathrm{pH}$ of 7.0 [8].

\section{Preparation and the range of calibration}

The chromatographic method was prepared to obtain working standards by the following points of the range:

Amoxicillin: $0.0012-0.0024-0.0048-0.012-$ $0.024-0.12 \mathrm{mg} / \mathrm{ml}$

Ampicillin: $0.0025-0.005-0.01-0.02-0.04$ $-0.1-1 \mathrm{mg} / \mathrm{ml}$

Ciprofloxacin: $0.001875-0.003-0.00325-$ $0.005025-0.0084 \mathrm{mg} / \mathrm{ml}$

In the microbiological technique, the following points of the range was prepared:

Ampicillin: $2.5-5-7.5-10-12.5 \mu \mathrm{g} / \mathrm{ml}$

Vancomycin: $10-20-30-35 \mu \mathrm{g} / \mathrm{ml}$ 


\section{Preparation of samples}

We had proceeded as follows for the determination of antibiotics by HPLC:

\section{Amoxicillin}

In a volume of $25 \mathrm{ml}$ of $\mathrm{H}_{2} \mathrm{O} \mathrm{R}$, we had immersed 25 disks of Amoxicillin/Clavulanic acid with an intense agitation and taking samples successively at 15, 30 and $45 \mathrm{~min}$.

\section{Ampicillin}

In a volume of $20 \mathrm{ml}$ of $\mathrm{H}_{2} \mathrm{O} \mathrm{R}$, we had immersed 20 disks of ciprofloxacin with an intense agitation and taking samples successively at 15, 30 and $45 \mathrm{~min}$.

\section{Ciprofloxacin}

In a volume of $20 \mathrm{ml}$ of $\mathrm{H}_{2} \mathrm{O}$ R, we had immersed 15 disks of ciprofloxacin with an intense agitation and taking samples successively at 15, 30 and $45 \mathrm{~min}$.

The microbiological method included five disks of every type of ATB were introduced into a volume of $5 \mathrm{ml}$ with an intense agitation during 45 minutes, and Mueller-Hinton culture medium was used in these experiments.

\section{Results}

\section{HPLC analysis}

The reference solutions were injected under the previous chromatographic conditions and the retention times were determined: amoxicillin $3.50 \mathrm{~min}$, ampicillin $6.20 \mathrm{~min}$ and ciprofloxacin $4.08 \mathrm{~min}$. The antibiotics concentrations in samples (Tables 2, 3 \& 4), respectively, were determined using prepared calibration curves for amoxicillin, ampicillin and ciprofloxacin. Figure 1 shows one example for preparation of antibiotic standards.

\section{Microbiological analysis}

The antibiotics concentrations in samples (Tables $\mathbf{5}$ \& 6) were determined by microbiological method using the calibration curves Diameter $=f(c)$; for ampicillin and vancomycin.

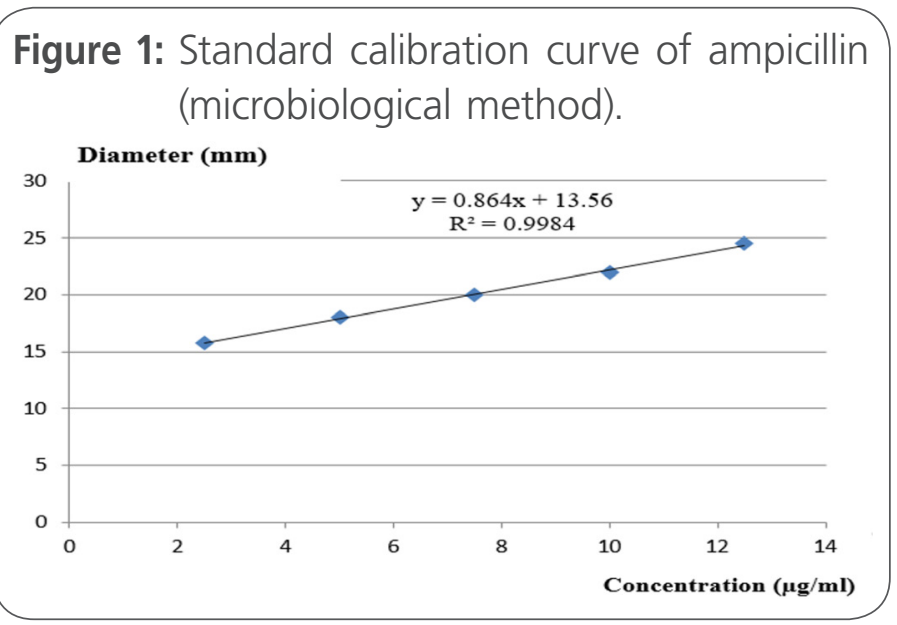

Table 2. Amoxicillin concentrations in samples.

\begin{tabular}{|l|c|c|c|c|c|}
\hline & AUC & \multicolumn{2}{|c|}{ Concentration } & \multicolumn{2}{c|}{ Content/disk } \\
\cline { 2 - 6 } & $\mathrm{U}$ & $\mathrm{mg} / \mathrm{ml}$ & $\mu \mathrm{g} / \mathrm{ml}$ & $\mu \mathrm{g}$ & $\%$ \\
\hline $\mathrm{E}_{5}{ }^{*}$ & 122226 & 0.0086 & 8.6 & 8.6 & 43 \\
\hline $\mathrm{E}_{12}$ & 85380 & 0.006 & 6 & 6 & 30 \\
\hline $\mathrm{E}_{13}$ & 166895 & 0.0118 & 11.8 & 11.8 & 59 \\
\hline $\mathrm{E}_{1}$ & 191249 & 0.0135 & 13.5 & 13.5 & 67.5 \\
\hline $\mathrm{E}_{8}$ & 85836 & 0.006 & 6 & 6 & 30 \\
\hline $\mathrm{E}_{2}$ & 62150 & 0.0044 & 4.4 & 4.4 & 22 \\
\hline & & & & $*$ *: Expired disk \\
\hline
\end{tabular}

Table 3. Ampicillin concentrations in samples.

\begin{tabular}{|l|c|c|c|c|c|}
\hline & AUC & \multicolumn{2}{|c|}{ Concentration } & \multicolumn{2}{c|}{ Content/disk } \\
\hline & $\mathrm{U}$ & $\mathrm{mg} / \mathrm{ml}$ & $\mu \mathrm{g} / \mathrm{ml}$ & $\mu \mathrm{g}$ & $\%$ \\
\hline $\mathrm{E}_{9}$ & 4683 & 0.0029 & 2.9 & 2.9 & 29 \\
\hline $\mathrm{E}_{6}{ }^{*}$ & 991 & 0.00073 & 0.73 & 0.73 & 7.3 \\
\hline $\mathrm{E}_{14}$ & 19859 & 0.0118 & 11.8 & 11.8 & 118 \\
\hline $\mathrm{E}_{15}$ & 16256 & 0.0097 & 9.7 & 9.7 & 97 \\
\hline & & & & & *: Expired disk \\
\hline
\end{tabular}

Table 4. Ciprofloxacin concentrations in samples .

\begin{tabular}{|l|c|c|c|c|c|}
\hline & AUC & \multicolumn{2}{|c|}{ Concentration } & \multicolumn{2}{c|}{ Content/disk } \\
\cline { 2 - 7 } & $\mathrm{U}$ & $\mathrm{mg} / \mathrm{ml}$ & $\mu \mathrm{g} / \mathrm{ml}$ & $\mu \mathrm{g}$ & $\%$ \\
\hline $\mathrm{E}_{3}$ & 554628 & 0.00414 & 4.14 & 5.52 & 110.4 \\
\hline $\mathrm{E}_{10}$ & 658196 & 0.0051 & 5.1 & 6.8 & 136 \\
\hline $\mathrm{E}_{16}$ & 656761 & 0.00509 & 5.09 & 6.78 & 135.6 \\
\hline
\end{tabular}


Table 5. Vancomycin concentrations in samples (Microbiological method).

\begin{tabular}{|c|c|c|c|c|}
\hline & Diameter & Concentration & \multicolumn{3}{|c|}{ Content/disk } \\
\hline $\mathrm{E}_{7}{ }^{*}$ & $\mathrm{~mm}$ & $\mu \mathrm{g} / \mathrm{ml}$ & $\mu \mathrm{g}$ & $\%$ \\
\hline $\mathrm{E}_{11}$ & 16.3 & 29.18 & 29.18 & 97.3 \\
\hline $\mathrm{E}_{17}$ & 15.1 & 23.87 & 23.87 & 79.6 \\
\hline $\mathrm{E}_{4}$ & 16.7 & 30.95 & 30.95 & 103.17 \\
\hline & 16.7 & 30.95 & 30.95 & 103.17 \\
\hline
\end{tabular}

Table 6. Ampicillin concentrations in samples (Microbiological method.

\begin{tabular}{|l|c|c|c|}
\hline & Diameter & Concentration & Content/disk \\
\hline $\mathrm{E}_{6}{ }^{*}$ & $\mathrm{~mm}$ & $\mu \mathrm{g} / \mathrm{ml}$ & $\%$ \\
\hline $\mathrm{E}_{14}$ & 23.6 & 0.5 & 5.1 \\
\hline $\mathrm{E}_{15}$ & 21.8 & 11.62 & 116.2 \\
$\mathrm{E}_{9}$ & 15.7 & 9.54 & 95.4 \\
& & 2.48 & 24.77 \\
\hline
\end{tabular}

Table 7. Ampicillin concentrations in samples determined by chromatographic and microbiological techniques.

\begin{tabular}{|l|c|c|c|c|}
\hline & HPLC & Microbiology & \multicolumn{2}{|c|}{ Difference of content } \\
\hline & $\mu g$ & $\mu g$ & $\mu g$ & $\%$ \\
\hline$E_{14}$ & 11.8 & 11.62 & 0.18 & 1.8 \\
\hline$E_{15}$ & 9.7 & 9.54 & 0.16 & 1.6 \\
\hline$E_{9}$ & 2.9 & 2.48 & 0.42 & 4.2 \\
\hline$E_{6}$ & 0.73 & 0.5 & 0.23 & 2.4 \\
\hline
\end{tabular}

\section{Discussion}

\section{Amoxicillin - Clavulanic acid $(20 / 10 \mu \mathrm{g})$}

Only amoxicillin was determined. All the results gave values lower than the reference indicated on the cartridges $(20 \mu \mathrm{g})$. The decrease in content varied between 32.5 and $78 \%$ (Table 2). It could be attributed to the hydrolysis of betalactamin, particularly of penicillin due to their known fragility.

\section{Ampicillin (10 $\mu \mathrm{g})$}

We obtained two results with normal deviations (3 and 18\%) and for the two others, E9 and E6 (expired cartridges), we had very low values and they contents were respectively $29 \%$ and $7.3 \%$.

\section{(Table 3)}

For E9, the decrease of the content could be caused by the non-respect of the conditions of the conservation and transport of the cartridges.

The expired cartridges were included in our work in the aim to prove their nonconformity for antibiogram tests.

\section{Ciprofloxacin $(5 \mu \mathrm{g})$}

One sample gave normal content and the two others values were superior to the normal content $(5 \mu \mathrm{g})$. These values were 35.6 and $36 \%$ superior to reference. (Table 4)

\section{Vancomycin $(30 \mu \mathrm{g})$}

In the European Pharmacopoeia $8^{\text {th }}$ Edition, there is no monograph for physicochemical determination of vancomycin; therefore, our reference in this work was the microbiological determination monograph.

The results were conform for three samples (E4, E11 and E17) and out of range for the fourth corresponding to expired cartridge E7 (Table 5). This technique was able to give us valuable results and prove that the expired cartridges are not valid.

\section{Expired disks}

All the results gave lower values than the reference. That is logically normal. Moreover, the results show that the content of expired disks decrease proportionally to the expired date.

\section{Unexpired disks}

In this work, the results of determination of antibiotics were diverse, ranging from normal to lower values.

The decrease of contents can be explained by poor or inappropriate storage conditions (tempera- 
ture and relative humidity), during the transport, the delivering circuit or during their use.

It is also important to have a desiccant in cartridges because -after opening- the disks could be exposed to an inappropriate atmosphere and an eventual absorption of moisture that could deteriorate their quality and decrease the antibiotic content. The same consequences could be observed when the disks were having a long stand in a non-sterile area (microbiological hood, near a Bunsen burner), that is why it is indicated on some of the notices to not exceed one week of use after opening the cartridges.

\section{Comparison of ampicillin determination by the two methods}

The physicochemical method (HPLC) has been used since 1970's and it is a technique for high precision determination $[5,6,7]$.

The difference between the results obtained by physicochemical and microbiological technics in the ampicillin determination is not significant (Tables 6 \& 7).

The microbiological test was done ten days after chromatography (HPLC). Moreover, a slight decrease of the content was observed in the microbiology results and confirm the change in the quality of disks after seven days opening, although the storage conditions were respected.

These methods can be complementary [8], and the HPLC, which is more precise, can be used to confirm or to cancel microbiology results in case of doubt.

\section{Conclusion}

The present work reveals the risk to find decrease content of antibiotic in the disks of antibiogram. Therefore, we must always apply strictly the storage conditions; temperature and relative humidity as well as conditions of the transport. In addition, a standard control bacteria strains should be used each time when susceptibility test done in vitro [9]. The cartridges should be used according to the expire date of the supplier recommendations. The expired disks must not be used, since our study demonstrated a clear decrease of their contents and they could give consequently false results. This study also shows the importance of correlation between chromatographic and microbiological methods and how it is important to encourage regular disk controls in all laboratories.

\section{Acknowledgements}

We are grateful to the National Laboratory of Control of medicine (LNCM) of Rabat. (Morocco) for accepting doing this study in the laboratory.

\section{References}

1. Smith P, O'Meara E, NcNulty D. Influence of disc content on zone sizes obtained in standard disc diffusion antimicrobial susceptibility tests. Aquaculture 2006; 261:799-803.

2. Tijare LK, Rangari NT, Mahajan UN. A review on bioanalytical method development and validation. Asian J Pharm Clin Res 2016; 9:6-10

3. Ashish M, Ajay KT. Formulation and evaluation of fast dissolving tablets of amoxycillin trihydrate and potassium clavulanate. Int J Curr Pharm Res 2017; 9:48-58.

4. Ramli Y, Radi M, El karbane M, El Alami A, Karrouchi K, Issmaili $S$ et Al. Optimization and validation of method for simultaneous determination of amoxicillin and clavulanic acid by HPLC in different pharmaceutical forms. Mor J Chem 2015; 3:58-64.

5. Gonnet C, Rocca JL. Séparation des produits pharmaceutiques par chromatographie en phase liquide en haute performance: influence de l'eau. J Chromatogr 1976; 120:419-433. 
6. Ishida M, Kobayashi K, Awata N, Sakamoto F. Simple high performance liquid chromatography determination of ampicillin in human serum using solid-phase extraction disk cartridges. J Chromatogr 1999; 727:245-248.

7. Gimet R, Filloux A. Identification et dosage d'alcaloïdes en mélange dans une forme pharmaceutique par chromatographie liquide haute performance. J Chromatogr A 1979; 177:333342.

8. Leroy P, Gavriloff C, Nicolas A. Comparative assay of amoxicillin by high performance liquid chromatography and microbiological methods for pharmacokinetic studies in calves. Int J Pharm 1992; 82:157-164.

9. Clinical Laboratory and Standards Institute (CLSI, 2015), Method for dilution antimicrobial susceptibility tests for bacteria that grow aerobically. CLSI, Villanova, PA, USA

Publish in The International Arabic Journal of Antimicrobial Agents

The Journal is an open access peer-reviewed journal that publishes scientific papers about all aspects of antimicrobials. The journal will publish original research articles, reviews, brief reports and case reports dealing with basic and clinical antibacterial agents, antiviral, antiprotozoals, antituberculuous, antifungal and antihelminthes agents. All manuscripts must be prepared in English, and are subject to a rigorous and fair peer-review process. Accepted papers will immediately appear online. The journal aims to advance the knowledge, attitude and the research of chemotherapy in the Arabic world in cooperation with international, national scientific and public societies as well as research centers with similar aims and objectives. 